\title{
Lower Blood Pressure Values in Blood Donors?
}

\author{
Edoardo Casiglia, MD, Renata Biasin, MD, \\ Gianni Cavatton,* MD, Marco Capuani, MD, \\ Alberto Marotri,* MD, Caterina Onesto, MD, \\ Paolo TRamontin, MD, \\ and Achille C. Pessina, MD, PhD
}

\section{SUMMARY}

594 blood donors were studied to define the influence of regular blood donation on blood pressure. Blood pressures were compared at the first phlebotomy performed at the Padova Blood Unit, the 13-year phlebotomy, and the median between the two. As a control population, a cohort of 594 non-donors from the same general population similar to the blood donors was studied twice at a 15 -year interval.

Subjects had made on average $7.3 \pm 0.4$ donations at the first step, $23 \pm 0.6$ at the second, and $30.9 \pm 0.7$ at the last step. Unadjusted systolic blood pressure regularly and significantly increased by $1.6 \%$ from the first phlebotomy to the second one and by $2.3 \%$ from the first to third. Adjusted systolic blood pressure, on the contrary, significantly decreased by $2.1 \%$ and by $2.7 \%$ respectively. Diastolic blood pressure tended to increase insignificantly, while the adjusted one did not change at all. The increase of systolic blood pressure from the first to second step directly correlated with the number of donations, and this also applied to differences between the first and the third. When the increase in age was introduced in the multiple regression analysis, systolic blood pressure rise from the first to third step showed an inverse correlation with the number of phlebotomies.

Our data render suspect the results of epidemiological investigations which took into consideration cohorts of blood donors; although these cohorts may be anagraphically representative of a general population, repeated phlebotomies introduce a bias leading to the detection of misleadingly low blood pressure values in regular blood donors. (Jpn Heart J 1996; 37: 897-903)

Key words: Phlebotomy Blood pressure Physiology Humans

\footnotetext{
From the Department of Clinical and Experimental Medicine, University of Padova, Padova, and the *Blood Transfusion Unit, General Hospital of Padova, Padova, Italy.

Address for correspondence: Edoardo Casiglia, MD, Department of Clinical and Experimental Medicine, University of Padova, Via Giustiniani, 2-35128 Padova, Italy.

Received for publication April 4, 1996.

Accepted June 17, 1996.
} 
7 ELATIONSHIPS between blood pressure (BP) and blood donation are unclear. The subtraction of $300-500 \mathrm{ml}$ of blood has an immediate hypotensive effect ${ }^{1-10}$ and phlebotomy is considered to be a good way of inducing a rapid and transient $B P$ fall. ${ }^{[1,12)}$ On the other hand, the long-term effects of repeated phlebotomies on $B P$ are essentially unknown.

This retrospective study was performed in a large group of normotensive blood donors whose BP history was recorded for 13 years in order to ascertain whether regular blood donation influences BP values. This could have practical importance as blood donation is widespread and involves millions of people worldwide: not only could the cardiovascular risk pattern of a great number of blood donors be modified by repeated blood lettings, but they could also require special attention to avoid misunderstandings when included in epidemiological studies.

\section{Methods}

Data from 594 blood donors who were referred to the Blood Transfusion Unit of the General Hospital of Padova were used in this study. Three blood pressures were taken into consideration: that in occasion of the first phlebotomy performed at the Padova Transfusion Center (this was not necessarily the first phlebotomy ever carried out), that in occasion of the 13-year phlebotomy, and the median between the previous two.

Systolic and diastolic BP in mmHg, body weight in $\mathrm{kg}$, body height in $\mathrm{m}$, number of blood lettings performed, and the interval in years from the first phlebotomy were recorded at each step. Body mass index (BMI) was calculated in $\mathrm{kg} \cdot \mathrm{m}^{-2}$ as the weight/height ratio. It must be emphasized that the routine of blood letting at the Padova Transfusion Center is organized in order to minimize any reaction, ${ }^{13,14)}$ in particular, blood donors stay in bed for at least 20 minutes prior to phlebotomy, BP is measured repeatedly (3 to 5 times), and only the last value is taken into consideration as the $\mathrm{BP}$ value. Although high $\mathrm{BP}$ values are considered by a great number of transfusion centers to be a contraindication to phlebotomy, this is not the policy of the Padova Center except in the cases of severe hypertension; nevertheless, no subject was excluded from the present study because of hypertension, and this meant that no confounding effect was introduced.

As a control population, a cohort of 594 non-donors from the same general population, demographically similar to the blood donors, was studied. Their BP was measured with the same method described above at a 15-year interval.

All subjects included in this study were non-diabetic and normotensive at the moment of the first donation (BP $<140 /<90 \mathrm{mmHg}$ ) and had never re- 


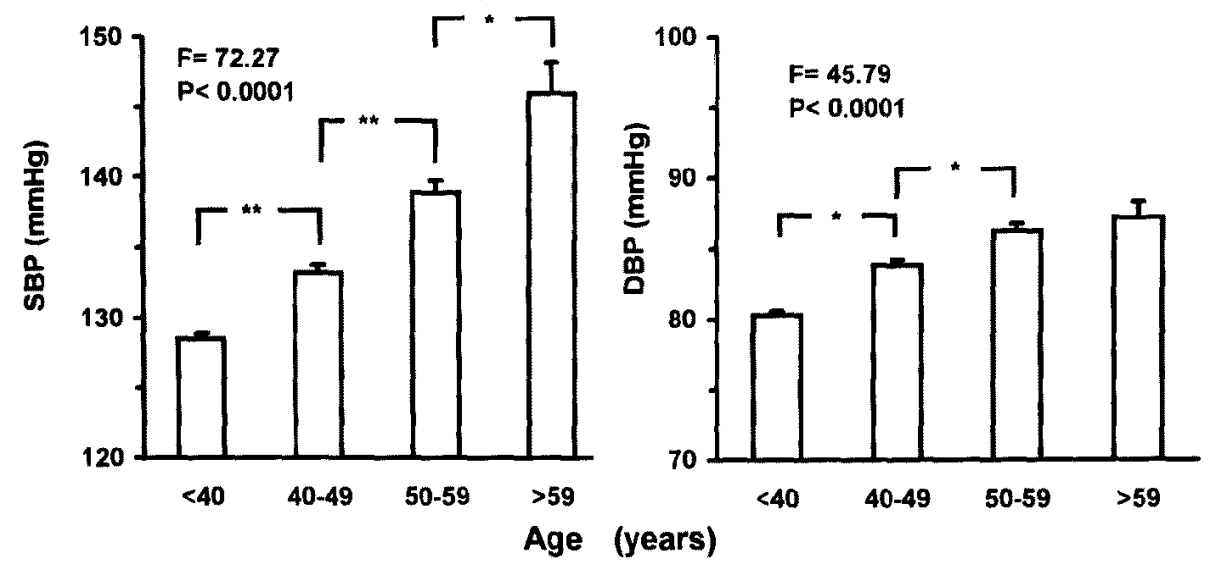

Figure 1. Blood pressure increase with age among the 594 blood donors. ${ }^{*} p<0.05$, $* p<0.01$.

ceived antihypertensive therapy.

Values were averaged and expressed as mean \pm standard error. As in blood donors, BP regularly increased with age (Figure 1). BP values of both cohorts were also age-adjusted. A repeated-measure analysis of variance was used in order to compare the means in the three steps, with Tukey's test as post hoc and Bonferroni's correction. Correlations were evaluated using the Pearson coefficient and Bonferroni's probability. The multiple correlation between the number of phlebotomies and systolic and diastolic BP was also performed using age as a covariate; results are expressed as multiple $\mathrm{R}$ and 2-tail $p$ value.

\section{Results}

Blood donors: Age of blood donors was $33.5 \pm 0.3$ years at the first step $(95 \%$ confidence limits [C.L.] 32.8-34.3), $43 \pm 0.4$ at the second (C.L. 42.2-43.9), and $46.5 \pm 0.43$ at the third (C.L. 45.7-47.4). BMI was similar in the three steps. Subjects had made on average $7.3 \pm 0.4$ donations at the first step (C.L. 6.6-8.1), $23 \pm 0.6$ at the second (C.L. 21.8-24.3), and 30.9 \pm 0.7 at the last step (C.L. 29.5-32.3). From the first to the second blood donation, $9.6 \pm 0.2$ years had passed (C.L. 9.2-10), and $13 \pm 0.2$ years had lapsed from the first to the third (C.L. 12.6-13.5).

Crude systolic BP regularly increased $(\mathrm{F}=6.75, p<0.001)$ by $1.6 \%$ from the first phlebotomy to the second and by $2.3 \%$ from the first to third (Figure 2, left panel). Adjusted systolic BP, on the contrary, decreased $(\mathrm{F}=8.56$, $p<0.00005$ ) by $2.1 \%$ and by $2.7 \%$, respectively (Figure 3, left panel). The effect of age was as follows: $\mathrm{F}=222.30, p<0.00005$. 

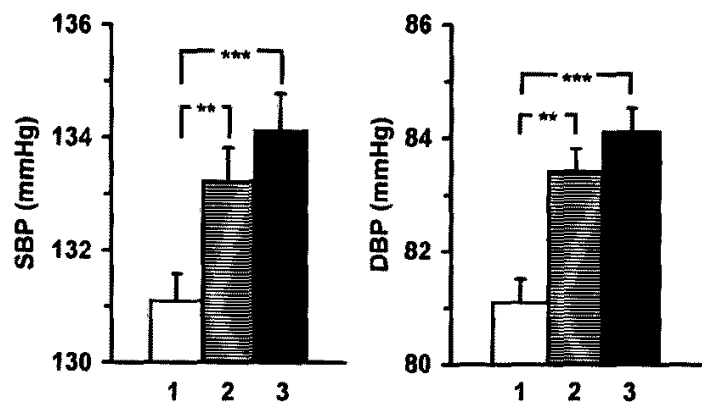

Figure 2. Crude mean values $\pm \mathrm{SE}$ of systolic (SBP, left panel) and diastolic (DBP, right panel) blood pressure at the first phlebotomy $(\square)$, at the last one $13 \pm 0.2$ years after the first ( $\square$ ) and at the median of the previous two $9.6 \pm 0.2$ years after the first (口). ANOVA: $\mathrm{F}=6.75, p<0.001$; post-hoc test: $* * p<0.01, * * *<<0.0001$.
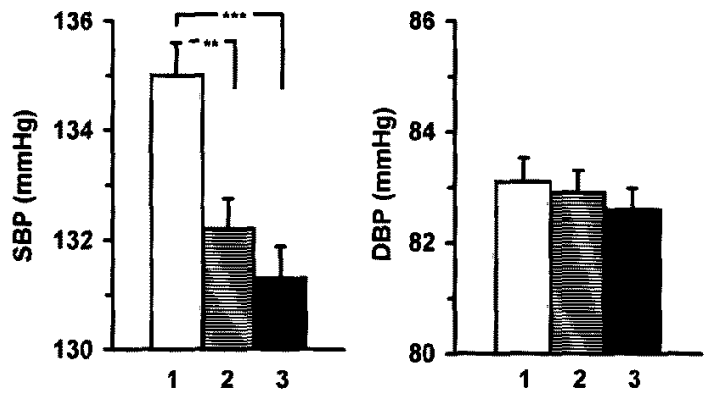

Figure 3. Age-adjusted mean values $\pm \mathrm{SE}$ of systolic (left panel) and diastolic (right panel) blood pressure. Legend as in Figure 2. ANOVA: $F=8.56, p<0.00005$; posthoc test $* * p<0.01, * * * p<0.0001$.

Crude diastolic BP tended to increase insignificantly (Figure 2, right panel) while the adjusted one did not change at all (Figure 3, right panel) (effect of age: $\mathrm{F}=133.79, p<0.00005$ ).

The increase of systolic BP from the first to second step directly correlated with the number of donations $(\mathrm{R}=0.135, p<0.005)$, and this also applied to the first and the third $(\mathrm{R}=0.115, p<0.01)$. When the increase in age was introduced in the multiple regression analysis, systolic BP rise from the first to third step showed an inverse correlation with the number of phlebotomies (multiple $\mathrm{R}=0.312$, coefficient $-0.084, p<0.05$; effect of age $p<0.005$ ), while any correlation at the second step was no longer evident.

Control subjects: Age of control subjects was $40.8 \pm 10.5$ at the first step and $55.6 \pm 10.5$ at the last $(\mathrm{F}=458.81, p<0.00005)$.

Age-adjusted systolic BP was $135.2 \pm 0.8$ and $135.4 \pm 0.7 \mathrm{mmHg}$, respectively (NS), and diastolic BP $82.2 \pm 0.5$ and $83.2 \pm 0.3 \mathrm{mmHg}$, respectively (NS). 


\section{Discussion}

Phlebotomy is an interesting human model of experimental hemorrhage. It is generally accepted that acute blood loss is accompanied or immediately followed by systemic vasodilatation ${ }^{15,16)}$ and a decrease in systolic and (less frequently) diastolic BP. ${ }^{1,2,4-10,15,17)}$ This is also our experience, ${ }^{11,17,18}$ but a stimulation of sympathetic discharge with an increase of systolic $\mathrm{BP},{ }^{19}$ heart rate, ${ }^{1,19)}$ plasma renin activity, adosterone, ACTH and norepinephrine ${ }^{10,11,17,20)}$ has also been described by other investigators both in humans and in the animal. BP fall has generally been attributed to hypovolemia, ${ }^{1,5,50)}$ based on the fact that similar effects were also observed after circulatory depletion due to diuretic treatment ${ }^{21)}$ or plasmapheresis, ${ }^{22)}$ that the greater the blood loss the higher the $\mathrm{BP}$ fall, ${ }^{23)}$ and that blood replacement sometimes has reversed the pressor effects of blood loss. ${ }^{15,17,21)}$ Hemodilution per se ${ }^{23)}$ and the phlebotomy-induced increase in the release of circulating substances such as bromocriptine ${ }^{24\}}$ could constitute additional hypotensive factors.

Sometimes the phlebotomy-induced BP fall lasts 24 hours or more ${ }^{2,11)}$ (even 4 weeks in the experience of Zidek et al, ${ }^{127}$ who hypothesize that phlebotomy can be used in addition to drug treatment in resistant essential hypertension), sometimes it is transitory. ${ }^{4,11,25)}$

The long-term effects of blood donation on BP are essentially unknown and the question of whether regular blood letting implies higher, lower or unchanged $B P$ values in blood donors remains unanswered. In our experience, regularly repeated blood donation was accompanied by a reduction in systolic BP. In fact, age-adjusted systolic BP regularly and significantly decreased by increasing the number of phlebotomies, being at the third step $2.7 \%$ lower than at the first (Figure 2). Diastolic BP did not change at all. The possibility that the systolic BP decrement was simply due to a progressive adaptation to $\mathrm{BP}$ measurement was excluded by the comparison with the control cohort of non-donors (where no variation was observed in 15 years of observation) and by the inverse correlation between adjusted $\mathrm{BP}$ and number of blood donations.

The reasons for the systolic $\mathrm{BP}$ decrease are difficult to define, as is its meaning. Literature on this topic is surprisingly poor and no data have been shown in humans. Susic et al. ${ }^{26)}$ found a statistically significant correlation between the hematocrit decrease and BP fall following repeated blood letting in rats (they concluded that there was a direct association between hematocrit and systemic hypertension), while other investigators found in rats, in similar experimental conditions, no influence on the physiogical pattern. ${ }^{27}$ In our experience BP decline was statistically significant, but it was not thought to be significant clinically. In any case, apart from their interest from a physiological point of view, our 
data render somewhat suspect the results of epidemiological investigations which included cohorts of blood donors, ${ }^{28-31)}$ although these cohorts may be anagraphically representative of a general population, repeated phlebotomies could introduce a procedural bias leading to the detection of misleadingly low BP values in regular blood donors.

A prospective study on BP changes following regular, repeated blood donation is in order.

\section{REFERENCES}

1. Kuchel AG, Avorn J, Reed MJ, Fields D. Cardiovascular responses to phlebotomy and sitting in middle-age and elderly subjects. Arch Intern Med 1992; 152: 366-70.

2. Meletti M, Gambarella A, Cotroneo G. Sulle modificazioni di alcune variabili neurovegetative nei donatori di sangue in rapporto al salasso. Acta Anasthesiol 1992; 17:61 1-24.

3. Marsch B, Cooper D. Phlebotomy and cardiac output measurement. J Cardiovasc Vasc Anesth 1992; 6: 122 .

4. Kennedy WF Jr, Bonica JJ, Akamatsu TJ, Ward RJ, Martin WE, Grinstein A. Cardiovascular and respiratory effects of subarachnoid block in the presence of acute blood loss. Anaestesiology 1968; 29: 29-35.

5. Markiewicz K, Cholewa M, Gorski L, Jaszczuk J, Chmura J, Bartniczak Z. Effect of $400 \mathrm{~m} /$ blood loss on adaptation of certain functions of the organism to exercise. Acta Phisiol Pol 1981; 32: 613-21.

6. Ionescu V, Costinescu M, Stoenescu L, Tarlea M, Arsenescu M. Cardiodynamic and electrocardiographic alterations induced by blood sampling in normal and hypertensive donors. Physiologie 1983; 20: 263-9.

7. Baraff LJ, Schriger DL. Orthostatic vital signs: Variation with age, specificity, and sensitivity in detecting a 450-ml blood loss. Am J Emerg Med 1992; 10: 99-103.

8. Kasprisin DO, Glynn SH, Taylor F, Miller KA. Moderate and severe reactions in blood donors. Transfusion 1992; 32: 23-6.

9. Adler PSJ, Ditto B, France C, France J. Cardiovascular reactions to blood donation in offspring of hypertensives and normotensives. J Psychosom Res 1994; 38: 429-39.

10. Velasquez MT, Menitove JE, Skelton MM, Cowley AWJr. Hormonal responses and blood pressure maintenance in normal and hypertensive subjects during acute blood loss. Hypertension 1987; 9: 42328.

11. Casiglia E, Vincenti E, Giacomello M, et al. B-endorphin levels after experimental blood loss in human subjects: Correlations with cortisol, ACTH, plasma renin activity, plasma catecholamines and blood pressure variations. Resuscitation 1989; 18: 141-3.

12. Zidek $W$, Tenschert $W$, Karoff $C$, Vetter $H$. Treatment of resistant hypertension by phlebotomy. Klin Wochensch 1985; 63: 762-4.

13. Wen SW, Kramer MS, Hoey J, Hanley JA, Usher RH. Terminal digit preference, random error, and routine bias in routine clinical measurement of blood pressure. J Clin Epidemiol 1993; 46: 1187-93.

14. Mancia G, Bertinieri G, Grassi G, Parati G, Pomidossi G, Ferrari A. Effects of blood pressure measurement by the doctor on patient's blood pressure and heart rate. Lancet 1983; 2: 695-7.

15. O'Shaugnessy L, Slome D. Aetiology of traumatic shock. Br J Surg 1934; 22: 589-618.

16. Silvani C, Zanella A, Rossi $\mathrm{F}$, et al. Effects of blood donation on cerebral blood flow velocity. Transfusion 1990; 30: 710-3.

17. Casiglia E, Angeli P, De Toni R, Gatta A, Pessina AC. ANP and PRA system response to phlebotomy. Am Heart J 1990; 6: 1485.

18. Casiglia E, Rossi A, Mazza A, et al. Hypnosis as a tool for evaluating the cortical component of haemodynamic variations: Pilot study during blood letting. High BP 1994; 3 (Suppl. 3): 8.

19. Martin S, Palmour RM, Goldwater R, et al. Characterization of a primate model of hypertension: 
The response of hypertensive and normotensive male vervets (Cercoipithecus aethiops) to cold pressor stress, captopril administration, and acute bolus of atrial natruretic factor. Am J Hypertension 1990; 3: $27-32$.

20. Chernow $B$, Lake $C R$, Barton $M$, et al. Sympathetic nervous system sensitivity to hemorragic hypotension in the subhuman primate. J Trauma 1984; 24: 229-32.

21. Shannon RP, Wey JY, Rosa RM, Epstein FH, Rowe JW. The effects of age and sodium depletion on cardiovascular response to orthostasis. Hypertension 1986; 8: 438-43.

22. Randels MJ, Strauss RG, Cordle D, Koerner TA, Floss AS. Donor reactions during DDAVP-stimulated plasmapheresis. J Clin Apheresis 1992; 7: 78-80.

23. Hyodo A, Heros RC, Tu YK, et al. Acute effects of isovolemic hemodilution with crystalloids in a canine model of focal cerebral ischemia. Stroke 1989; 20: 534-40.

24. Lanza V, Palazzadriano M, Scardulla C, Mercadante S, Valdes L, Bellanca G. Hemodynamics, prolactin and catecholamine levels during hemorragic shock in dogs pretreated with a prolactin inhibitor (bromocriptine). Pharmacol Res Comm 1987; 19: 307-18.

25. Kirwan T, Chir B, Scurr CBE, Brindle Smith G. Cardiovascular changes during controlled blood loss and replacement. Anaesthesia 1981; 36: 1127-9.

26. Susic D, Mandal AK, Kentera D. Hemodynamic effects of chronic alteration in hematocrit in spontaneously hypertensive rats. Hypertension 1984; 6: 262-6.

27. Furuhama $K$, Kato $M$, Suzuki $N$, Igarashi $K$, Onodera $T$. The influence of single or repeated phlebotomy on the physiological condition of normal and diseased rats. J Toxicol Sci 1987; 12: 1-9.

28. Bellodi $G$, Bernini $G$, Manicardi $V$, et al. Ipertensione arteriosa in rapporto allo stile di vita e altri fattori di rischio cardiovascolare: Studio epidemiologico in una popolazione di donatori di dangue. Progetto AVIS. Min Cardioangiol 1994; 42: 73-84.

29. Turner ST, Johnson M, Boerwinkle E, Richelson E, Taswell HF, Sing CF. Sodium-lithium countertransport and blood pressure in healthy blood donors. Hypertension 1985; 7: 955-62.

30. Baldys-Waligorska A, Szybinski Z. Plasma endothelin levels in healthy blood donors and in hypertensive patients: Clinical application. Endocr Regul 1993; 27: 83-7.

31. Köhler T, Scherbaum N, Ritz T. Psychophysiological responses of borderline hypertensives in two experimental situations. Psychoter Psychosom 1995; 63: 44-53. 